\title{
Can water insufflation and carbon dioxide overcome the difficulties of colonoscope insertion?
}

\author{
Choong-Kyun Noh, Kee Myung Lee \\ Department of Gastroenterology, Ajou University School of Medicine, Suwon, Korea
}

\section{Article: Difficult colonoscopy: air, carbon dioxide, or water insufflation? (Intest Res 2018;16:299- 305)}

Colonoscopy is the best diagnostic tool for colon polyp, cancer, and IBD. Appropriate luminal distention and reduction of patient discomfort are essential for visualization of the entire colon mucosa. ${ }^{1,2}$ The total insufflated air volume during colonoscopy is typically 8 to $18 \mathrm{~L}^{3}$ Air insufflation (AI) can cause pain and discomfort, especially when the scope is passed through the movable peritoneal portion of the colon. Several methods, including the carbon dioxide $\left(\mathrm{CO}_{2}\right)$ insufflation method and the water assistance method (water immersion $[\mathrm{WI}]$, water exchange $[\mathrm{WE}]$ ), have been introduced to relieve patient discomfort.

$\mathrm{CO}_{2}$ is absorbed across the bowel 160 times faster than nitrogen and 13 times faster than oxygen. ${ }^{4}$ A study showed that $\mathrm{CO}_{2}$ causes less pain and discomfort than AI during colonoscopy. ${ }^{4}$ In this study, the $\mathrm{CO}_{2}$ group showed no significant residual gas on plain radiographs after colonoscopy and much less discomfort than the air group, which showed large amounts of gas on radiographs. After this study, more than 20 randomized controlled trials on the effectiveness of $\mathrm{CO}_{2}$ versus air have been published. $\mathrm{CO}_{2}$ was seen to be superior to air for reducing post-procedural pain and flatus in the immediate and delayed periods after colonoscopy. ${ }^{5}$ However, when performing colonoscopy, $\mathrm{CO}_{2}$ did not show an improvement in the cecal intubation time or rate compared with air. ${ }^{6}$

The basic concept of WI and WE is that water is insufflated

Received March 7, 2018. Revised March 7, 2018. Accepted March 7, 2018. Correspondence to Kee Myung Lee, Department of Gastroenterology, Ajou University School of Medicine, 206 World cup-ro, Yeongtong-gu, Suwon 16499, Korea. Tel: +82-31-219-5119, Fax: +82-31-219-5999, E-mail: Ikm5104@ajou.ac.kr instead of gas to distend the colon. ${ }^{7}$ A bowel filled with water becomes less distended and its angulation is reduced compared to that with air. After the scope reaches the cecum, the water is removed with suction and mucosal inspection is performed during the withdrawal phase. The water insufflation method is known to have several advantages; namely, speeding up intubation, higher cecal intubation and adenoma detection rate, and lower patient discomfort than AI.

Comparing the effect of water and $\mathrm{CO}_{2}$, many studies have shown that patient pain and discomfort was better relieved with water than with $\mathrm{CO}_{2}{ }^{8}$ This particular study was twoarm and designed to compare groups of water and air, $\mathrm{CO}_{2}$ and air, or water and $\mathrm{CO}_{2}{ }^{8}$ This study included ordinary patients and excluded difficult cases such as patients with a history of abdominal surgery or severe variations in body weight such as obesity or very low body weight. Few studies have compared the superiority of insufflation methods in difficult patients. There are certain limitations in applying the results from ordinary cases to patients with risk factors.

The current issue of Intestinal Research includes a report by Chaubal et al..$^{9}$ describing a prospective randomized study comparing the clinical efficiency of air, $\mathrm{CO}_{2}$, and water insufflation in difficult colonoscopies. This study included patients with a BMI $<18 \mathrm{~kg} / \mathrm{m}^{2}$ or $>30 \mathrm{~kg} / \mathrm{m}^{2}$ and previous abdominal or pelvic surgeries. ${ }^{9}$ The authors conducted a three-armed study to compare the effectiveness of the air, $\mathrm{CO}_{2}$, and water methods including patients with risk factors. ${ }^{9}$ The primary endpoint (no sedation, cecal intubation, visual analog scale [VAS] score $<5$ ) was reached in $31.8 \%, 45 \%$, and $84 \%$ in the air, water, and $\mathrm{CO}_{2}$ groups respectively $(P<0.001$; water being significantly better than air $[P<0.001]$ and $\mathrm{CO}_{2}$

๑ Copyright 2018. Korean Association for the Study of Intestinal Diseases. All rights reserved.

This is an Open Access article distributed under the terms of the Creative Commons Attribution Non-Commercial License (http://creativecommons.org/licenses/by-nc/4.0)

which permits unrestricted non-commercial use, distribution, and reproduction in any medium, provided the original work is properly cited. 
$[P=0.001])$. The mean pain scores were $5.17,4.72$, and 3.93 on the VAS scale for air, $\mathrm{CO}_{2}$, and water insufflation $(P<0.001)$ with significant difference between water and air $(P<0.001)$ and water and $\mathrm{CO}_{2}(P=0.001)$ but not $\mathrm{CO}_{2}$ and air $(P=0.090)$. They compared the primary endpoint and pain score according to risk factors and endoscopic location in the colon. Among the risk factors, the $\mathrm{BMI}<18 \mathrm{~kg} / \mathrm{m}^{2}$ group showed the lowest primary endpoint and the highest pain score. Water insufflation most effectively reduced the VAS score in the $\mathrm{BMI}<18 \mathrm{~kg} / \mathrm{m}^{2}$ group and the pain when the endoscope is passed through the rectosigmoid and splenic flexure. ${ }^{9}$

Based on the results of this study, water insufflation can relieve pain and discomfort during and after colonoscopy not only in ordinary patients but also in patients with risk factors that might lead to a difficult colonoscopy. Some studies reported that the WE method is more effective than the WI in ordinary patients. ${ }^{10}$ Further studies are needed on the usefulness of the WE method and the simultaneous WI with CI method with patients with risk factors.

\section{FINANCIAL SUPPORT}

The authors received no financial support for the research, authorship, and/or publication of this article.

\section{CONFLICT OF INTEREST}

No potential conflict of interest relevant to this article was reported.

\section{AUTHOR CONTRIBUTION}

Conceptualization: N.C.K., K.M.L. Writing-original draft: N.C.K., K.M.L. Review and editing: K.M.L. Approval of final manuscript: all authors.

\section{REFERENCES}

1. Lee HS, Byeon JS. Bowel preparation, the first step for a good quality colonoscopy. Intest Res 2014;12:1-2.

2. Chun CG, Kim HG, Jeon SR, Ko BM, Lee BH, Kim JO. Analysis of colonoscopy quality in clinical practices of Korea: cohort study of patients referred to tertiary hospital after colonoscopy examinations. Intest Res 2013;11:198-203.

3. GE Technology Assessment Committee, Maple JT, Banerjee S, et al. Methods of luminal distention for colonoscopy. Gastrointest Endosc 2013;77:519-525.

4. Saltzman HA, Sieker HO. Intestinal response to changing gaseous environments: normobaric and hyperbaric observations. Ann N Y Acad Sci. 1968;150:31-39.

5 . Wu J, Hu B. The role of carbon dioxide insufflation in colonoscopy: a systematic review and meta-analysis. Endoscopy 2012;44:128-136.

6. Memon MA, Memon B, Yunus RM, Khan S. Carbon dioxide versus air insufflation for elective colonoscopy: a meta-analysis and systematic review of randomized controlled trials. Surg Laparosc Endosc Percutan Tech 2016;26:102-116.

7. Baumann UA. Water intubation of the sigmoid colon: water instillation speeds up left-sided colonoscopy. Endoscopy 1999;31:314-317.

8. Pohl J, Messer I, Behrens A, Kaiser G, Mayer G, Ell C. Water infusion for cecal intubation increases patient tolerance, but does not improve intubation of unsedated colonoscopies. Clin Gastroenterol Hepatol 2011;9:1039-1043.e1.

9. Chaubal A, Pandey V, Patel R, et al. Difficult colonoscopy: air, carbon dioxide, or water insufflation? Intest Res 2018;16:299305.

10. Hsieh YH, Koo M, Leung FW. A patient-blinded randomized, controlled trial comparing air insufflation, water immersion, and water exchange during minimally sedated colonoscopy. Am J Gastroenterol 2014;109:1390-1400. 